\title{
Retraction Note to: A Novel Voting Mathematical Rule Classification for Image Recognition
}

\author{
Sadrollah Abbasi ${ }^{(\bowtie)}$, Afshin Shahriari, and Yaser Nemati \\ Department of Computer Engineering, \\ Iran Health Insurance Organization, Yasouj, Iran \\ sadrollahsadeghi@gmail.com, yasernamati@gmail.com
}

\section{Erratum to:}

Chapter 20 in: O. Gervasi et al. (Eds.)

Computational Science and Its Applications - ICCSA 2016

DOI: 10.1007/978-3-319-42092-9_20

This paper has been retracted as its contents were plagiarized from "AVNM: A Voting based Novel Mathematical Rule for Image Classification" by Ankit Vidyarthi and Namita Mittal, published by Elsevier Ltd. in 2015. 


\title{
Retraction Note to: Clustering of Wikipedia Texts Based on Keywords
}

\author{
Jalalaldin Gharibi Karyak ${ }^{1}$, Fardin Yazdanpanah Sisakht ${ }^{1}$, \\ and Sadrollah Abbasi ${ }^{2}$ \\ ${ }^{1}$ Technical and Vocational University, Yasooj, Iran \\ \{gharibi.jalal92, fyazdanpanah14\} @gmail.com \\ ${ }^{2}$ Department of Computer Engineering, \\ Iran Health Insurance Organization, Yasouj, Iran \\ sadrollahsadeghi@gmail.com
}

\section{Erratum to:}

Chapter 39 in: O. Gervasi et al. (Eds.)

Computational Science and Its Applications - ICCSA 2016

DOI: 10.1007/978-3-319-42092-9_39

This paper has been retracted as its contents were plagiarized from "Spectral Clustering Wikipedia Keyword-based Search Results" by Julian Szymański and Tomasz Dziubich, submitted to Frontiers in September 2015. 